\title{
Thomas Witulski
}

\section{Apk 11 und der Bar Kokhba-Aufstand}

\author{
Eine zeitgeschichtliche Interpretation
}

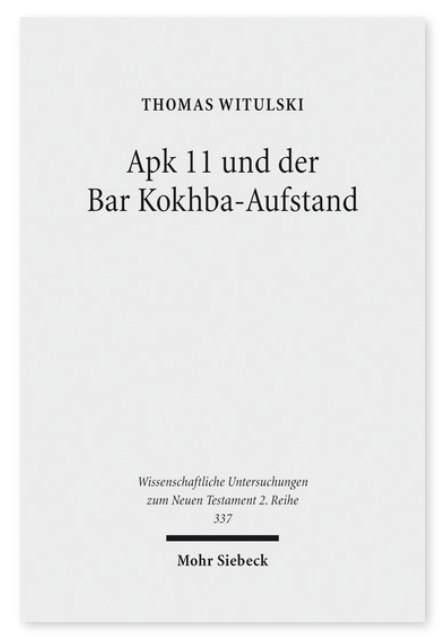

2012. XII, 355 Seiten. WUNT II 337

ISBN 978-3-16-152290-1

DOI 10.1628/978-3-16-152290-1

eBook PDF 104,00€

ISBN 978-3-16-152182-9

fadengeheftete Broschur 104,00€
Thomas Witulski überprüft die These der Datierung der Abfassung der Johannesapokalypse in die Zeit zwischen 132 und 135 n. Chr. an Apk 11,1-13 auf ihre Tragfähigkeit. Wird dieser Text auf dem Boden dieser neuen Datierung der Apk zeitgeschichtlich interpretiert, lassen sich viele bis dahin kaum befriedigend erklärte Probleme seiner Auslegung zwanglos lösen: Mit seinen Ausführungen in Apk 11 bezieht sich der Apokalyptiker auf den zwischen 132 und 135 n. Chr. zu datierenden Bar Kokhba-Aufstand. Die beiden in Apk 11 auftretenden »Zeugen« repräsentieren Bar Kokhba und den Priester El'azar, den politischen und den geistlichen Führer dieses zweiten jüdischen Krieges gegen Rom. Nach anfänglichen Erfolgen wird die von innen initiierte Rebellion von dem »Tier aus dem Abgrund«, dem römischen Kaiser Hadrianus, niedergeschlagen; die Führer der Aufständischen verlieren ihr Leben, Jerusalem, die heilige Stadt, wird zerstört.

Thomas Witulski Geboren 1964; Studium der Ev. Theologie, Philosophie und Geschichtswissenschaft in Münster; 1998 Promotion zum Dr. theol.; 2005 Habilitation; 2012 Promotion zum Dr. phil. (Alte Geschichte); seit 2009 Vertretung der Lehrstuhls für Biblische Theologie und ihre Didaktik an der Universität Bielefeld.

Jetzt bestellen:

https://mohrsiebeck.com/buch/apk-11-und-der-bar-kokhba-aufstand-9783161522901?no_cache=1 order@mohrsiebeck.com

Telefon: $+49(0) 7071-923-17$

Telefax: +49 (0)7071-51104 